\title{
A Combined Model for Predicting Engineering Identity in Undergraduate Students
}

\section{Anita D. Patrick, University of Texas, Austin}

Anita Patrick is a STEM Education doctoral student and Graduate Research Assistant in the Department of Mechanical Engineering and College of Liberal Arts at UT Austin's Population Research Center. She received her BS in Bioengineering from Clemson University where she tutored undergraduate mathematics and science courses, and mentored undergraduate engineering majors. Prior to coming to UT, she independently tutored K12 and undergraduate mathematics and science. Her research interests include engineering education, identity and equity. Address: Engineering Training Center II (ETC) 204 East Dean Keeton Street Austin, TX 78712 Email: apatrick@utexas.edu

\section{Dr. Maura Borrego, University of Texas, Austin}

Maura Borrego is Professor of Mechanical Engineering and STEM Education at the University of Texas at Austin. She previously served as a Program Director at the National Science Foundation, on the board of the American Society for Engineering Education, and as an associate dean and director of interdisciplinary graduate programs. Her research awards include U.S. Presidential Early Career Award for Scientists and Engineers (PECASE), a National Science Foundation CAREER award, and two outstanding publication awards from the American Educational Research Association for her journal articles. Dr. Borrego is Deputy Editor for Journal of Engineering Education. All of Dr. Borrego's degrees are in Materials Science and Engineering. Her M.S. and Ph.D. are from Stanford University, and her B.S. is from University of Wisconsin-Madison.

\section{Dr. Carolyn Conner Seepersad, University of Texas, Austin}

Associate Professor of Mechanical Engineering 


\title{
A Combined Model for Predicting Engineering Identity in Undergraduate Students
}

\begin{abstract}
Several recent studies have focused on measures of student attitudes and beliefs to predict outcomes such as career choice, integration, persistence, and identity in engineering. The body of research on identity in engineering education has converged around a framework based on three factors: performance/competence (i.e., ability or beliefs that one can perform well or understands concepts), interest in the subject matter, and recognition by others (i.e., peers, family members, teachers) as the type of person who can understand/complete the subject matter. Prior studies have shown math and physics identity factors to be predictive of engineering major choice in first-year undergraduates. However, these studies have not included engineering identity factors. The first aim of this paper is to test a combined model for predicting engineering identity. The combined model includes previously established factors of math and physics identity and newly established engineering factors of the same kind. The second aim is to compare this combined model to a model using only engineering factors to investigate the usefulness of these factors as stand-alone predictors of engineering identity.

The study draws on data collected from 1202 undergraduate engineering students in three majors across two public institutions in the southwestern United States. Using linear regression, the results show that all three domains (math, physics, and engineering) individually account for a significant proportion of the variance in engineering identity after controlling for student demographic variables. The combined model explained a total of $29.1 \%$ of the variance in engineering identity. Of the non-engineering factors, only math performance/competence was a significant predictor. However, all three engineering factors were significant predictors in that model. Comparatively, the standalone model using just the engineering factors explained nearly the same proportion of variance in engineering identity as the combined model, $28.9 \%$. These findings indicate that while students' math and physics beliefs are important to predicting engineering identity, their engineering beliefs provide equivalent explanatory power. Future research would be better informed through an understanding of how these three domain areas contribute to our understanding of identity and other outcomes.
\end{abstract}

\section{Introduction}

Engineering is a diverse discipline demanding skill and competency in such areas as math and applied sciences (e.g., applied physics). The interdisciplinary nature of engineering calls into question the extent to which those participating in the community of practice - students as well as professionals - see themselves as engineers. The lack of alignment of one's personal identity and the identity of an engineer may cause some to feel as if they do not belong. It is well documented that engineering disciplines have low female and minority representation (Chemers, Zurbriggen, Syed, Goza, \& Bearman, 2011; Chubin, May, \& Babco, 2005; Faulkner, 2009; Hill, Corbett, \& St Rose, 2010). Though men and women leave engineering at similar rates, women have been found to leave at an earlier stage than men (Godwin \& Potvin, 2015; Min, Zhang, Long, Anderson, \& Ohland, 2011) and less than a quarter of all engineering degrees are awarded to women (Ohland et al., 2008). Similarly, underrepresented racial and ethnic minorities represent fewer than $20 \%$ of engineering student populations in the United 
States (Chubin et al., 2005). Perhaps some of this representation is due to the lack of these groups identifying with the field of engineering, as suggested by Tonso (2014) in her review of engineering identity.

Identity as a construct has been defined and measured in various ways across a diverse body of literature (Patrick \& Borrego, 2016). Such definitions include an integration of multiple identities such as social, personal and academic (Chemers et al., 2011); "being recognized as a 'certain type' of person" (Gee, 2000); how students see themselves with respect to a content area, based on their perceptions and navigation of everyday experiences in that area (Cribbs, Cass, Hazari, Sadler, \& Sonnert, 2016); and a composite of students' performance, competence, and recognition in a domain (Carlone $\&$ Johnson, 2007). The last definition is the focus of this current study. This composite definition emerged from Carlone and Johnson's (2007) qualitative study on science identity as the triangulation of performance, competence, and recognition in science. Performance describes a student's belief in their ability to perform in their classes or to conduct tasks. Similarly, competence describes a student's belief in their ability to understand content. Performance and competence are closely linked. In later quantitative studies of identity, these factors were combined into one performance/competence factor, thus reflecting student's self-perception of performance as linked to their actual performance. Recognition describes how parents, relatives, friends, and instructors see the student in a given context. This framework was expanded by Hazari, Sonnert, Sadler, and Shanahan (2010) in their quantitative analysis of physics identity with the addition of interest to the framework. Interest describes one's enjoyment in learning or interest in learning about engineering. The PCIR framework refers to the performance/competence, interest, and recognition framework, collectively throughout this paper.

Despite the expanding use of this PCIR framework, few studies treat engineering identity as an outcome variable. As the popularity of studying identity in engineering builds, we can point to several other studies that have employed the PCIR framework to study math identity, science identity, and physics identity (Cass, Hazari, Cribbs, Sadler, \& Sonnert, 2011; Cribbs et al., 2016; Cribbs, Hazari, Sonnert, \& Sadler, 2015; Godwin, Potvin, \& Hazari, 2013; Godwin, Potvin, Hazari, \& Lock, 2013). Quantitative work largely treats the identity construct as a stepping stone to examine STEM career interest (Kier, Blanchard, Osborne, \& Albert, 2014) or choice of engineering career (Cribbs et al., 2016; Godwin, Potvin, Hazari, et al., 2013; Lent et al., 2008; Sheppard, Antonio, Brunhaver, \& Gilmartin, 2014; Sheppard et al., 2010) in high school or first-year undergraduate students. In this study, we focus on students in their first year and beyond to add to the body of literature on engineering undergraduates (Godwin, 2016; Godwin, Potvin, Hazari, \& Lock, 2016). Specifically, the aim of this study is to simultaneously explore the PCIR framework in the context of math, physics, and engineering and examine the effects on engineering identity in undergraduate engineering students across their trajectory to matriculation.

\section{Methods}

This study is a cross-sectional examination of engineering identity through the application of the PCIR framework to three domain areas: math, physics, and engineering. Data on engineering identity is particularly lacking for students beyond their first year; therefore we examine students at the freshman, sophomore, junior, and senior 
levels. Godwin and Lee (Godwin \& Lee, 2017) demonstrated that the use of similar identity measures is appropriate for undergraduate students across all levels.

\section{Instrument Administration and Participants}

The survey, which took approximately fifteen minutes to complete, was administered in class on paper during the first four weeks of the fall 2016 semester in undergraduate engineering courses in civil engineering $(\mathrm{CE})$, architectural engineering (AE), mechanical engineering (ME), and biomedical engineering (BME) courses. Architectural and civil engineering students are in the same department and share many required courses; for this analysis, they were grouped together (collectively labeled CE). The setting was two public institutions in the southwestern United States, referred to as predominately white institution (PWI) and Hispanic serving institution (HSI). Surveys were administered to equal numbers of lower-division (freshman and sophomore level) and upper-division (junior and senior level) courses.

A total of 1465 participants consented to the survey, of which 1202 responses were retained for the purposes of this analysis. Only participants with complete responses to the items in the analyses were included. In the instance of students with a double major, they were retained if one major was CE, ME, or BME. The final data set was $66 \%$ male and 34\% female. Based on first semester of enrollment, $27.5 \%$ were freshmen, $28.1 \%$ were sophomores, $22.0 \%$ were juniors, and $22.4 \%$ were seniors. The racial/ethnic composition of the sample was 40.5\% White; 31.0\% Hispanic; $19.8 \%$ Asian; $4.7 \%$ Other International/Foreign; 2.8\% American Indian, Native Hawaiian, or two or more races; and $1.2 \%$ Black. All demographic data was gathered from institutional records.

\section{Instrument Development}

We created the domain area PCIR scales from items used in previous survey studies of identity (Prybutok, Patrick, Borrego, Seepersad, \& Kirisits, 2016). To create our independent variables, we used items from Sustainability and Gender in Engineering (SaGE) (Godwin, Potvin, Hazari, et al., 2013) and Hazari et al.(Hazari et al., 2010). SaGE contained the phrasing of items as seen in Table 1. To generate the three domain areas for our survey we replaced the word "subject" with "math", "physics", or "engineering" to form three sets of questions that addressed performance/competence, interest, and recognition for each domain area. Our dependent variable is a newly created two-item engineering identity scale consisting of one visual and one verbal item relating to the extent to which respondents believe their personal identity overlaps with the identity of an engineer (Borrego, Patrick, Martins, \& Kendall, 2018). This factor was on a scale of "1: far apart/not at all" to "8: complete overlap/ to a great extent."

Additionally, we gathered several student variables as controls. Participants selfidentified the highest level of education completed by their mother; this factor was used as a surrogate to control for socioeconomic status. Additionally, we collected demographic data including gender, classification, major, race, and first semester of enrollment from university records after survey administration. We also controlled on institution type, PWI vs. HSI, which is important to model specification and generalizability of findings. 
Table 1. Question Phrasing of Independent Variables

\begin{tabular}{l|l}
\hline Construct & Item \\
\hline Performance/ & $\begin{array}{l}\text { I can understand concepts I have studied in this subject } \\
\text { I am confident that I can understand this subject in class } \\
\text { I can overcome setbacks in this subject } \\
\text { I am confident that I can understand this subject outside of class } \\
\text { I can do well on exams in this subject } \\
\text { Others as me for help in this subject }\end{array}$ \\
\hline Interest & $\begin{array}{l}\text { I enjoy learning this subject } \\
\text { I am interested in learning more about this subject }\end{array}$ \\
\hline Recognition & $\begin{array}{l}\text { Do the following see you as a subject?* } \\
\text { Parents } \\
\text { Relatives } \\
\text { Friends }\end{array}$ \\
\hline
\end{tabular}

*The participants responded to the question separately for parents, relatives, and friends.

\section{Data Analysis}

Data analysis was conducted using Stata Statistical Software (StataCorp LP, 2015, Release 14, College Station, TX). We examined the relationship between our dependent and independent variables by analyzing a Pearson Correlation matrix of the variables. In total, we ran five regression models. Model I was the baseline containing only control variables. Subsequent models contained math PCIR (Model II), physics PCIR (Model III), engineering PCIR (Model IV), and all three domain areas (Model V). Each of these models tested the effects of the controls and the domain area factors as independent variables on engineering identity. All domain areas factors were measured on a Likert scale from 1 for "Strongly Disagree" to 5 for "Strongly Agree". To make interpretation meaningful in the model, all independent variables were standardized to have a mean of zero and standard deviation of one. For consistency across all models, only participants with observations on all variables for each factor were included in the model to ensure that the same group was compared across each factor.

We created several control variables for our models. Gender was dummy coded as 0 for male and 1 for female. Institution type was also dummy coded; 0 for PWI and 1 for HSI. Similarly, race/ethnicity was coded as 0 and 1 for the absence or presence of each response category respectively. Major was a factor-level variable coded as 0 for ME, 1 for CE, and 2 for BME. Student classification was partitioned by division (freshman and sophomore $=0$; junior and senior $=1$ ). Mother's education was a categorical variable coded as 1 for "graduated from high school equivalent, GED, or less", 2 for "Degree or certificate from a vocational school, a junior college, a community college, or another type of 2-yr. school", 3 for "Completed a College degree", and 4 for "Completed a Masters, Doctoral or other advanced professional degree (JD, MD, PhD, etc.)." 


\section{Results}

\section{Pearson Correlations}

Table 2 shows the Pearson correlations between the dependent and independent variables and descriptive statistics for those variables on their original scale. Note the alpha reliability for all the variables (Table 2, far right column) was above the acceptable level of 0.70 . On average students reported a moderate overlap between their personal identity and the identity of an engineer as indicated by a mean of 5.19 out of 8 on engineering identity. The students also rated themselves highly on the PCIR factors with all means ranging from 3.54 to 4.37 out of 5 .

Carefully examining the correlation matrix, we see high associations within domain areas. Specifically, the highest association occurs between interest and performance/competence. While we cannot assume a causal relationship, we do know there is a strong relationship between interest and performance/competence in math $(\mathrm{r}=0.67)$, physics $(\mathrm{r}=0.70)$, and engineering $(\mathrm{r}=0.60)$. This likely reflects the relationship between perceived ability and feelings of enjoyment. All other correlations within domain areas were 0.47 or less.

Between domain areas, we see strong correlations within the PCIR framework. For example, engineering performance/competence is highly correlated with physics performance/competence $(\mathrm{r}=0.66)$, and math performance/competence $(\mathrm{r}=0.59)$. Similarly, recognition in one domain is highly correlated with another. This result is slightly disrupted when looking at interest between domain areas, in which the correlations (ranging from 0.44 to 0.49 ) are moderate to borderline strong.

Shifting the focus to engineering identity, the outcome variable, we see a range of correlations (Table 2, first column). The strongest correlations to engineering identity are engineering interest $(\mathrm{r}=0.43)$, and performance/competence $(\mathrm{r}=0.37)$. Comparatively, physics performance/competence, physics interest, and engineering recognition each have about the same relationship to engineering identity $(\mathrm{r} \sim 0.30)$. The weakest correlation to engineering identity is math recognition $(\mathrm{r}=0.17)$. The overall implication here is that while there are strong correlations within domain areas, there are also strong correlations across domain areas suggesting students may be identifying with the broader constructs of performance/competence, interest, and recognition at an aggregate level. 
Table 2. Correlations, Means, Standard Deviations, and Alpha Reliability of Independent and Dependent Variables

\begin{tabular}{|c|c|c|c|c|c|c|c|c|c|c|c|c|c|c|}
\hline & & 1) & 2) & 3) & 4) & 5) & 6) & 7) & 8) & 9) & 10) & $\mathrm{M}$ & SD & $\propto$ \\
\hline & $\begin{array}{l}\text { 1) Engineering } \\
\text { Identity }\end{array}$ & - & & & & & & & & & & 5.19 & 1.36 & 0.84 \\
\hline & $\begin{array}{l}\text { 2) Performance/ } \\
\text { Competence }\end{array}$ & $.21 *$ & - & & & & & & & & & 4.00 & .72 & 0.90 \\
\hline \multirow[t]{3}{*}{ Math } & 3) Interest & $.25^{*}$ & $.67 *$ & - & & & & & & & & 3.85 & .94 & 0.83 \\
\hline & 4) Recognition & $.17^{*}$ & $.36^{*}$ & $.31 *$ & - & & & & & & & 4.21 & .80 & 0.84 \\
\hline & $\begin{array}{l}\text { 5) Performance/ } \\
\text { Competence }\end{array}$ & $.29 *$ & $.52 *$ & $.40^{*}$ & $.17 *$ & - & & & & & & 3.63 & .83 & 0.92 \\
\hline \multirow[t]{3}{*}{ Physics } & 6) Interest & $.30^{*}$ & $.36^{*}$ & $.44^{*}$ & $.12 *$ & $.70^{*}$ & - & & & & & 3.59 & 1.06 & 0.87 \\
\hline & 7) Recognition & $.24^{*}$ & $.17^{*}$ & $.10 *$ & $.51^{*}$ & $.47^{*}$ & $.39 *$ & - & & & & 3.54 & .99 & 0.89 \\
\hline & $\begin{array}{l}\text { 8) Performance/ } \\
\text { Competence }\end{array}$ & $.37 *$ & $.59 *$ & $.37 *$ & $.18^{*}$ & $.66^{*}$ & $.45^{*}$ & $.29^{*}$ & - & & & 3.92 & .68 & 0.88 \\
\hline \multirow[t]{2}{*}{ Engineering } & 9) Interest & $.43^{*}$ & $.42 *$ & $.48^{*}$ & $.16^{*}$ & $.39 *$ & $.49^{*}$ & $.18^{*}$ & $.60^{*}$ & - & & 4.37 & .77 & 0.81 \\
\hline & 10) Recognition & $.30^{*}$ & $.16^{*}$ & $.13 *$ & $.52 *$ & $.16^{*}$ & $.11 *$ & $.51 *$ & $.28 *$ & $.26^{*}$ & - & 4.05 & .82 & 0.79 \\
\hline
\end{tabular}

${ }^{*} p<.001$. 


\section{Linear Regression}

Results of the linear regression models are presented in Table 3. Model I

(baseline) shows there are significant differences in engineering identity based on gender, institution type, and mother's education. This trend was observed across all models except for Models II (math), IV (engineering), and V (full model). However, institution type was the most significant across all models with students at the HSI rating their engineering identity higher than that of students at the PWI. Notably, institution type is the strongest predictor of engineering identity in all the models. We also see a curious gender finding, in which the physics PCIR factors (Model III) help to decrease the gender gap between males and females; whereas, the gender gap is the same or worse in the other models, including the full model (see Table 3, row 1 under Controls).

In the math model (Model II), only math interest $(\mathrm{p} \leq 0.001)$ and math recognition $(\mathrm{p} \leq 0.001)$ are significant predictors of engineering identity. Both of these variables have a similar effect on the outcome with a one-point increase in either variable translating into approximately a fifth of a standard deviation increase in engineering identity. This model accounts for a total of $13.9 \%$ of the variance in engineering identity. The baseline (controls) model alone accounts for the majority of this variance, $8.1 \%$. Physics PCIR, however, has a different effect on engineering identity. All factors are statistically significant in the analysis (Model III). Unlike the math and engineering models, physics recognition is the highest predictor of engineering identity amongst the PCIR factors. Overall, the physics factors account for an additional $8.1 \%$ of the variance from the baseline model. The total variance accounted for in Model III is $16.2 \%$. Finally, we see a large jump in the proportion of variance explained in Model IV. The engineering PCIR factors alone explain $20.8 \%$ of the variance in engineering identity when controls are included this total increases to $28.9 \%$. As reflected by the correlation matrix, engineering interest has the strongest relationship to engineering identity. The coefficient $(\beta=0.36)$ is the largest amongst all the PCIR factors in Models II, III, and IV. In sum, engineering PCIR factors explain 3.6 times the variance in engineering identity compared to math, and 2.6 times the variance in engineering identity compared to physics.

With the inclusion of each of the domain areas in the final model (Model V) we see that all the engineering factors are still statistically significant $(\mathrm{p} \leq 0.001)$, and retain nearly identical predictive power as seen in the engineering only model (Model IV). The only other PCIR factor that is significant in the final model is math performance/competence. However, the coefficient $(\beta=-0.12)$ is negative indicating an increase in perceptions of confidence and ability in math results in a decrease in engineering identity. In comparison, the physics coefficients are virtually zero and insignificant. The final model containing controls and the PCIR factors from all three domain areas accounts for $29.1 \%$ of the variance in engineering identity, making the contribution of the math and physics factors negligible $(0.2 \%)$. 
Table 3. Linear regression predicting engineering identity

\begin{tabular}{|c|c|c|c|c|c|}
\hline & $\begin{array}{l}\text { Model I } \\
\text { Baseline } \\
\text { Model }\end{array}$ & $\begin{array}{l}\text { Model II } \\
\text { Baseline \& } \\
\text { Math }\end{array}$ & $\begin{array}{c}\text { Model III } \\
\text { Baseline \& } \\
\text { Physics }\end{array}$ & $\begin{array}{c}\text { Model IV } \\
\text { Baseline \& } \\
\text { Engineering }\end{array}$ & $\begin{array}{c}\text { Model V } \\
\text { Full } \\
\text { Model }\end{array}$ \\
\hline \multicolumn{6}{|c|}{ Controls } \\
\hline \multirow[t]{2}{*}{ Gender } & $-0.29 * * *$ & $-0.35 * * *$ & $-0.18 *$ & $-0.29 * * *$ & $-0.27 * * *$ \\
\hline & 0.08 & 0.08 & 0.08 & 0.07 & 0.08 \\
\hline \multirow[t]{2}{*}{ Major (CE) } & -0.06 & -0.03 & 0.08 & -0.15 & -0.12 \\
\hline & 0.10 & 0.10 & 0.10 & 0.09 & 0.09 \\
\hline \multirow[t]{2}{*}{ Major (BME) } & -0.03 & -0.04 & 0.09 & -0.06 & -0.04 \\
\hline & 0.11 & 0.10 & 0.10 & 0.10 & 0.10 \\
\hline \multirow{2}{*}{$\begin{array}{l}\text { Classification } \\
\text { (fr. \& soph.) }\end{array}$} & -0.07 & $-0.14 \sim$ & -0.07 & -0.10 & $-0.12 \sim$ \\
\hline & 0.08 & 0.08 & 0.07 & 0.07 & 0.07 \\
\hline \multirow[t]{2}{*}{ Institution } & $0.62 * * *$ & $0.64 * * *$ & $0.57 * * *$ & $0.52 * * *$ & $0.51^{* * *}$ \\
\hline & 0.14 & 0.13 & 0.13 & 0.12 & 0.12 \\
\hline \multirow[t]{2}{*}{ Black } & -0.15 & -0.15 & -0.03 & 0.10 & 0.14 \\
\hline & 0.35 & 0.34 & 0.34 & 0.31 & 0.31 \\
\hline \multirow[t]{2}{*}{ Hispanic } & 0.15 & 0.08 & 0.16 & 0.06 & 0.07 \\
\hline & 0.11 & 0.11 & 0.11 & 0.10 & 0.10 \\
\hline \multirow[t]{2}{*}{ Asian } & 0.02 & 0.12 & 0.09 & $0.20^{*}$ & $0.21 *$ \\
\hline & 0.10 & 0.10 & 0.10 & 0.09 & 0.09 \\
\hline \multirow[t]{2}{*}{ Other } & 0.34 & 0.28 & 0.22 & 0.20 & 0.16 \\
\hline & 0.23 & 0.22 & 0.22 & 0.20 & 0.20 \\
\hline \multirow{2}{*}{$\begin{array}{l}\text { Mother's } \\
\text { Education }\end{array}$} & $-0.08^{*}$ & -0.05 & $-0.09 *$ & $-0.06 \sim$ & $-0.06 \sim$ \\
\hline & 0.04 & 0.04 & 0.04 & 0.03 & 0.03 \\
\hline \multicolumn{6}{|c|}{ Math } \\
\hline \multirow{2}{*}{$\begin{array}{l}\text { Performance/ } \\
\text { Competence }\end{array}$} & & $0.08 \sim$ & & & $-0.12 *$ \\
\hline & & 0.05 & & & 0.06 \\
\hline \multirow{2}{*}{ Interest } & & $0.19 * * *$ & & & $0.10 \sim$ \\
\hline & & 0.05 & & & 0.05 \\
\hline \multirow{2}{*}{ Recognition } & & $0.15^{* * *}$ & & & -0.00 \\
\hline & & 0.04 & & & 0.05 \\
\hline
\end{tabular}




\begin{tabular}{|c|c|c|c|c|c|}
\hline \multicolumn{6}{|c|}{ Physics } \\
\hline \multirow{2}{*}{$\begin{array}{l}\text { Performance/ } \\
\text { Competence }\end{array}$} & & \multicolumn{3}{|c|}{$0.13^{*}$} & 0.01 \\
\hline & & \multicolumn{3}{|c|}{0.05} & 0.06 \\
\hline \multirow{2}{*}{ Interest } & & \multicolumn{3}{|c|}{$0.17 * * *$} & 0.01 \\
\hline & & \multicolumn{3}{|c|}{0.05} & 0.06 \\
\hline \multirow{2}{*}{ Recognition } & & \multicolumn{3}{|c|}{$0.20 * * *$} & 0.07 \\
\hline & & \multicolumn{3}{|c|}{0.04} & 0.05 \\
\hline \multicolumn{6}{|c|}{ Engineering } \\
\hline \multirow{2}{*}{$\begin{array}{l}\text { Performance/ } \\
\text { Competence }\end{array}$} & & & & $0.17 * * *$ & $0.19 * * *$ \\
\hline & & & & 0.04 & 0.06 \\
\hline \multirow{2}{*}{ Interest } & & & & $0.36 * * *$ & $0.34 * * *$ \\
\hline & & & & 0.04 & 0.05 \\
\hline \multirow{2}{*}{ Recognition } & & & & $0.29 * * *$ & $0.25 * * *$ \\
\hline & & & & 0.04 & 0.04 \\
\hline \multirow{2}{*}{ Constant } & $5.39 * * *$ & $5.34 * * *$ & $5.31 * * *$ & $5.39 * * *$ & $5.38 * * *$ \\
\hline & 0.15 & 0.14 & 0.14 & 0.13 & 0.13 \\
\hline Adjusted $\mathrm{R}^{2}$ & 0.081 & 0.139 & 0.162 & 0.289 & 0.291 \\
\hline
\end{tabular}

$\mathrm{N}=1202 \sim \mathrm{p} \leq 0.10 ; * \mathrm{p} \leq 0.05 ; * * \mathrm{p} \leq 0.01 ; * * * \mathrm{p} \leq 0.001$

\section{Discussion and Conclusions}

Our work expands on previous research in several ways. We examine the effect of the PCIR framework within three domain areas (math, physics, and engineering) on engineering identity. Furthermore, our analytical sample includes students from each phase in their undergraduate study, rather than focusing on first-year students. These are important steps in advancing research on engineering student identity. As this is the first study of its kind, we did not have a means of direct comparison for our results. However, the results of this study are promising as they illuminate the factors most important to engineering identity: gender, institution type, engineering performance/competence, engineering interest, engineering recognition, and math performance/competence. The fact that the other PCIR factors were not significant in the final model can be attributed to the high correlations between the factors both within and between domain areas. This truth is most evident in the negligible increase in the variance explained from Model IV $(28.9 \%)$ to $\mathrm{V}(29.1 \%)$, meaning the math and physics PCIR factors do not uniquely explain any additional variance in engineering identity. In other words, the engineering PCIR factors are sufficient for modeling engineering identity without the inclusion of math or physics factors.

Although all of the PCIR factors were significant predictors in these models, it was institution type that had the biggest impact. This is important when accounting for that fact that major, student classification (lower vs. upper division), race, and mother's education (a surrogate for socioeconomic status) were controlled for in this analysis. Campus culture is an important factor in the construction of engineering identity as students learn to define themselves within their community (Tonso, 2006). Similarly, 
gender construction and its relationship to engineering identity could be a reflection of campus culture, gender norms, or stereotyping within engineering. The remaining factors comprising the PCIR framework perhaps have a more intuitive relationship to engineering identity. Performance/competence, interest, and recognition all share positive significant correlations. Therefore, building confidence in students' ability to perform and understand engineering tasks will likely increase their interest in engineering. In turn, this could increase the likelihood a student will identify himself or herself as or be identified as an engineer.

Examining our findings across domain areas, interest is the major influencer on identity. This is consistent with previous findings. Those with high levels of sense of self within engineering also tend to report high levels of interest (enjoyment) (Matusovich, Streveler, \& Miller, 2010). More work on this construct in engineering education can help us better understand interest and its relationship to identity and persistence. Engineering performance/competence is also important to measuring engineering identity. For instance, Jones, Osborne, Paretti, and Matusovich (2014) found a positive relationship between perceived ability and identity. As this area of research progresses, clear distinctions should be made between performance/competence and other similar constructs in the literature such as self-efficacy. The significance of recognition in the models of engineering identity points to a type of support that may be critical to engineering identity development. For example, role models and mentors have been cited as beneficial in fostering a desire to pursue engineering and other STEM disciplines (Buontempo, Riegle-Crumb, Patrick, \& Peng, 2017; Marra, Rodgers, Shen, \& Bogue, 2009; Nauta, Epperson, \& Kahn, 1998). These findings can be particularly impactful for women and race/ethnic minorities in the case of same-race or same-gender mentoring (Blake - Beard, Bayne, Crosby, \& Muller, 2011; Blickenstaff, 2006; Burke \& Mattis, 2007; Fleming, Smith, Williams, \& Bliss, 2013). While we do not make claims in relation to mentoring, we do report the cumulative importance of recognition by family, friends, and peers to students' engineering identity.

In future work, modeling engineering identity with these factors in conjunction with qualitative work on students' perceptions of engineering could provide more insights into what contributes to students' identification with engineering. There are a few limitations to note in this study. The sample was drawn from only three departments across two institutions and cannot claim to be generalizable to the broader engineering student population. Both departments (i.e., differences between engineering disciplines) and campus culture are topics for future research. Additionally, the theoretical framework was based on math and science identity work and does not address the professional aspects of engineering that are likely important to identity (Patrick et al., 2017). Nonetheless, this study builds on the foundation of prior studies of STEM identity. As engineering identity frameworks are further refined we can start to investigate the ongoing work of identity formation amongst individuals and groups, thus broadening our understanding of what it means to be an engineer.

\section{Acknowledgements}

This research was funded by the National Science Foundation through grants \#1636449 and \#1636404. The authors wish to thank department chairs, faculty members, instructors, and students who made the collection of this data possible. Any opinions, 
findings, and conclusions in this article are the authors' and do not necessarily reflect the views of the National Science Foundation.

\section{References}

Blake-Beard, S., Bayne, M. L., Crosby, F. J., \& Muller, C. B. (2011). Matching by race and gender in mentoring relationships: Keeping our eyes on the prize. Journal of Social Issues, 67(3), 622-643.

Blickenstaff, J. C. (2006). Women and science careers: Leaky pipeline or gender filter? Gender and Education, 17(4), 369-386. doi:10.1080/09540250500145072

Borrego, M., Patrick, A., Martins, L., \& Kendall, M. (2018). A New Scale for Measuring Engineering Identity in Undergraduates. Paper presented at the 2018 ASEE GulfSouthwest Section Annual Conference Austin, TX.

Buontempo, J., Riegle-Crumb, C., Patrick, A., \& Peng, M. (2017). Examining Gender Differences in Engineering Identity among High School Engineering Students. Journal of Women and Minorities in Science and Engineering, 23(3).

Burke, R. J., \& Mattis, M. C. (2007). Women and minorities in science, technology, engineering, and mathematics: Upping the numbers. Cheltenham, UK: Edward Elgar Publishing.

Carlone, H. B., \& Johnson, A. (2007). Understanding the science experiences of successful women of color: Science identity as an analytic lens. Journal of Research in Science Teaching, 44(8), 1187-1218. doi:10.1002/tea.20237

Cass, C. A. P., Hazari, Z., Cribbs, J., Sadler, P. M., \& Sonnert, G. (2011). Examining the impact of mathematics identity on the choice of engineering careers for male and female students. Paper presented at the Frontiers in Education Conference Rapid City, SD.

Chemers, M. M., Zurbriggen, E. L., Syed, M., Goza, B. K., \& Bearman, S. (2011). The role of efficacy and identity in science career commitment among underrepresented minority students. Journal of Social Issues, 67(3), 469-491.

Chubin, D. E., May, G. S., \& Babco, E. L. (2005). Diversifying the engineering workforce. Journal of Engineering Education, 94(1), 73-86.

Cribbs, J., Cass, C. A. P., Hazari, Z., Sadler, P. M., \& Sonnert, G. (2016). Mathematics identity and student persistence in engineering. International Journal of Engineering Education, 32(1(A)), 163-171.

Cribbs, J., Hazari, Z., Sonnert, G., \& Sadler, P. M. (2015). Establishing an explanatory model for Mathematics Identity. Child development, 86(4), 1048-1062.

Faulkner, W. (2009). Doing gender in engineering workplace cultures. I. Observations from the field. Engineering Studies, 1(1), 3-18.

Fleming, L. N., Smith, K. C., Williams, D. G., \& Bliss, L. B. (2013). Engineering identity of Black and Hispanic undergraduates: The impact of minority serving institutions. Paper presented at the American Society for Engineering Education Annual Conference, Atlanta, GA.

Gee, J. P. (2000). Identity as an analytic lens for research in education. Review of research in education, 25(1), 99-125.

Godwin, A. (2016). The development of a measure of engineering identity. Paper presented at the American Society for Engineering Education Annual Conference, New Orleans, LA. 
Godwin, A., \& Lee, W. (2017). A cross-sectional study of engineering identity during undergraduate education. Paper presented at the American Society for Engineering Education Annual Conference, Columbus, $\mathrm{OH}$.

Godwin, A., \& Potvin, G. (2015). Fostering female belongingness in engineering through the lens of critical engineering egency. International Journal of Engineering Education, 31(4), 938-952.

Godwin, A., Potvin, G., \& Hazari, Z. (2013). The development of critical engineering agency, identity, and the impact on engineering career choices Paper presented at the American Society for Engineering Education Annual Conference, Atlanta, GA.

Godwin, A., Potvin, G., Hazari, Z., \& Lock, R. (2013). Understanding engineering identity through structural equation modeling. Paper presented at the Frontiers in Education Conference, Oklahoma City, OK.

Godwin, A., Potvin, G., Hazari, Z., \& Lock, R. (2016). Identity, critical agency, and engineering: An affective model for predicting engineering as a career choice. Journal of Engineering Education, 105(2), 312-340.

Hazari, Z., Sonnert, G., Sadler, P. M., \& Shanahan, M.-C. (2010). Connecting high school physics experiences, outcome expectations, physics identity, and physics career choice: A gender study. Journal of Research in Science Teaching, 47(8), 978-1003. doi:10.1002/tea.20363

Hill, C., Corbett, C., \& St Rose, A. (2010). Why so few? Women in science, technology, engineering, and mathematics: ERIC.

Jones, B. D., Osborne, J. W., Paretti, M. C., \& Matusovich, H. M. (2014). Relationships among students' perceptions of a first-year engineering design course and their engineering identification, motivational beliefs, course effort, and academic outcomes. International Journal of Engineering Education, 30(6), 1340-1356.

Kier, M. W., Blanchard, M. R., Osborne, J. W., \& Albert, J. L. (2014). The development of the STEM career interest survey (STEM-CIS). Research in Science Education, 44(3), 461-481.

Lent, R. W., Sheu, H.-B., Singley, D., Schmidt, J. A., Schmidt, L. C., \& Gloster, C. S. (2008). Longitudinal relations of self-efficacy to outcome expectations, interests, and major choice goals in engineering students. Journal of Vocational Behavior, 73(2), 328-335. doi:10.1016/j.jvb.2008.07.005

Marra, R. M., Rodgers, K. A., Shen, D., \& Bogue, B. (2009). Women engineering students and self-efficacy: A multi-year, multi-institution study of women engineering student self-efficacy. Journal of Engineering Education, 98(1), 2738.

Matusovich, H. M., Streveler, R. A., \& Miller, R. L. (2010). Why do students choose engineering? A qualitative, longitudinal investigation of students' motivational values. Journal of Engineering Education, 99(4), 289-303.

Min, Y., Zhang, G., Long, R. A., Anderson, T. J., \& Ohland, M. W. (2011). Nonparametric survival analysis of the loss rate of undergraduate engineering students. Journal of Engineering Education, 100(2), 349-373.

Nauta, M. M., Epperson, D. L., \& Kahn, J. H. (1998). A multiple-groups analysis of predictors of higher level career aspirations among women in mathematics, 
science, and engineering majors. Journal of Counseling Psychology, 45(4), 483496.

Ohland, M. W., Sheppard, S. D., Lichtenstein, G., Eris, O., Chachra, D., \& Layton, R. A. (2008). Persistence, engagement, and migration in engineering programs. Journal of Engineering Education, 97(3), 259-278.

Patrick, A., \& Borrego, M. (2016). A Review of the Literature Relevant to Engineering Identity. Paper presented at the American Society for Engineering Education Annual Conference, New Orleans, LA.

Patrick, A., Choe, N., Martins, L., Borrego, M., Kendall, M., \& Seepersad, C. (2017). A measure of affect toward key elements of engineering professional practice. Paper presented at the American Society for Engineering Education Annual Conference, Columbus, $\mathrm{OH}$.

Prybutok, A., Patrick, A., Borrego, M., Seepersad, C. C., \& Kirisits, M. J. (2016). Crosssectional survey study of undergraduate engineering identity. Paper presented at the American Society for Engineering Education Annual Conference, New Orleans, LA.

Sheppard, S., Antonio, A. L., Brunhaver, S. R., \& Gilmartin, S. (2014). Studying the career pathways of engineers. In A. Johri \& B. M. Olds (Eds.), Cambridge handbook of engineering education research (pp. 283-309). New York: Cambridge University Press.

Sheppard, S., Gilmartin, S., Chen, H. L., Donaldson, K., Lichtenstein, G., Eris, O., . . . Toye, G. (2010). Exploring the engineering student experience: findings from the academic pathways of people earning engineering survey (APPLES). TR-10-01. Center for the Advancement of Engineering Education (NJ1).

Tonso, K. L. (2006). Teams that work: Campus culture, engineer identity, and social interactions. Journal of Engineering Education, 95(1), 25-37.

Tonso, K. L. (2014). Engineering identity. In A. Johri \& B. Olds (Eds.), Cambridge handbook of engineering education research (pp. 267-282). New York, NY: Cambridge University Press. 